\title{
Pseudomicetoma dermatofítico: relato de um caso devido a Trichophyton tonsurans
}

\author{
Dermatophytic pseudomycetoma: report of a case \\ caused by Trichophyton tonsurans
}

\section{Mário A.P. Moraes', Achilles Alves Levy Machado1, Plínio Medeiros Filho'e Carmélia Matos Santiago Reis}

Resumo É descrito um caso de pseudomicetoma dermatofítico, recidivante, em paciente com lesões no couro cabeludo. O exame histopatológico de uma das lesões mostrou, nos tecidos, os agregados micelianos ou pseudogrânulos, característicos da enfermidade. Dos tecidos frescos de outras lesões foi isolado o dermatófito Trichophyton tonsurans. Exames micológicos adicionais falharam em demonstrar a existência de tinea capitis, possível fonte do pseudomicetoma. A raridade dessa forma de dermatofitose profunda justifica a presente publicação.

Palavras-chaves: Pseudomicetoma dermatofítico. Micetoma dermatofítico. Foliculite fúngica. Trichophyton tonsurans.

Abstract A case of dermatophytic pseudomycetoma, in a patient with a history of recurrent lesions in the scalp, for over two years, is reported. Histopathological examination of the affected tissues revealed the mycelial aggregates or pseudogranules characteristic of the disease. Cultures of fresh tissues samples detected a fungus identified as Trichophyton tonsurans. Additional examinations failed to demonstrate lesions of tinea capitis, a probable source of the deep infection. Dermatophytic pseudomycetoma is an extremely rare form of dermatophytosis, and the rarity of such cases is the motive for the present communication.

Key-words: Dermatophytic pseudomycetoma Dermatophytic mycetoma. Fungal folliculitis. Trichophyton tonsurans.

Dermatofitoses ou dermatofitias são afecções cutâneas, geralmente circunscritas, do homem e de animais domésticos, causadas por diversos fungos ceratinofílicos denominados em conjunto dermatófitos - um termo hoje impróprio, mas já sancionado pelo uso. Os fungos desse grupo (cerca de vinte espécies, combinadas em grande número de espectros regionais), quando no estado anamórfico ou assexuado, pertencem a três diferentes gêneros dos Deuteromicetos ou Fungi imperfecti: Microsporum, Trichophyton e Epidermophyton. Apesar da distância taxonômica, têm eles em comum, além da ceratinofilia e de alguma semelhança nas características microscópicas, a propriedade de colonizar estruturas ceratinizadas camada córnea da epiderme, pêlos e unhas - do tegumento dos hospedeiros. Como se trata de estruturas inertes, as alterações provocadas usualmente pelos dermatófitos resultam de uma reação, desenvolvida nos tecidos vizinhos, contra produtos do metabolismo fúngico antes que da presença dos microrganismos invasores nas partes ceratinizadas. A gravidade das manifestações, em conseqüência, depende mais do estado imunitário, ou seja, do grau de sensibilização do hospedeiro a esses produtos, do que da espécie ou cepa do dermatófito em causa.

As dermatofitoses compreendem uma extensa variedade de condições clínicas distintas. As mais comuns foram incluídas nas micoses cutâneas, sob o nome genérico de tinhas (do latim tinea), e classificadas de acordo com a localização: Tinea capitis, Tinea corporis, Tinea barbae, Tinea unguium, Tinea pedis, Tinea manuum e Tinea cruris.

Em raras ocasiões, os dermatófitos invadem as camadas mais profundas, não ceratinizadas, da pele ou, mesmo, a hipoderme, onde despertam uma resposta aguda, com formação de abscessos, que pode dar lugar a uma inflamação granulomatosa de tipo corpo estranho. Admite-se que a invasão se faça a partir de folículos infectados, por ruptura da parede folicular. A ruptura ocorreria em virtude da ação de três fatores: pressão

1. Centro de Anatomia Patológica do Hospital Universitário de Brasília, Brasília, DF.

Endereço para correspondência: Dr. Mário A.P. Moraes. Centro de Anatomia Patológica/Hospital Universitário de Brasília. Via L2 Norte, SGAN604/605, Módulo C, 70840-050 Brasília, DF.

Fax: $5561307-1588$

Recebido para publicação em 26/9/2000. 
exercida pelo crescimento miceliano dentro do folículo, distendendo a parede folicular; perfuração da parede por fragmentos de pêlos parasitados que sofreram fratura; e reação inflamatória intensa perifolicular, capaz de destruir o epitélio da parede.

A passagem de artroconídios e hifas para o conjuntivo em torno do folículo é causa de inflamação supurativa e granulomatosa, cuja intensidade depende do estado de sensibilização do hospedeiro. Várias entidades clínicas, as dermatofitoses ou tinhas profundas, com essa patogenia, têm sido descritas: quério, favo, granuloma tricofítico de Majocchi, perifoliculite nodular (granuloma perifolicular), sicose tricofítica (parasitária) e foliculite abscedente de Hoffmann (foliculite dissecante do couro cabeludo). Elas devem ser consideradas como foliculites dermatofíticas, tendo em conta a origem de todas na ruptura dos folículos invadidos por dermatófitos. Padilha-Gonçalves ${ }^{7}$ sugeriu que as lesões piogranulomatosas, dérmicas e subcutâneas, causadas por dermatófitos deveriam ser agrupadas sob o título único de dermatofitias granulomatosas.

Uma entidade pouco conhecida, devido à raridade dos casos, é o chamado micetoma ou pseudomicetoma dermatofítico. Nesse tipo de dermatofitose profunda, também de origem folicular, os fungos, ao invadirem a derme, em vez de conservar a forma de elementos hifais e artroconídios, dão origem a massas lobuladas, constituídas por agregados micelianos, frouxamente entrelaçados e envolvidos por matriz homogênea e eosinofílica. Alguns autores consideraram esses agregados de hifas como grânulos (grãos), semelhantes aos dos micetomas, e deram à infecção o nome de micetoma dermatofítico. Ajello e col${ }^{1}$, entretanto, são de opinião que os agregados diferem, em vários aspectos, dos grãos observados nos micetomas verdadeiros, e propuseram para eles o nome de pseudogrânulos e para a infecção, o de pseudomicetoma dermatofítico.

\section{RELATO DO CASO}

Paciente do sexo feminino, 23 anos, parda, doméstica, oriunda do Estado de Tocantins, mas residente em Planaltina, DF. Veio à consulta, no Hospital Universitário de Brasília, em janeiro de 2000 , queixandose de tumoração recidivante no couro cabeludo, surgida havia mais de dois anos. Após crescer por quase sete meses e atingir $3 \mathrm{~cm}$ de diâmetro, foi a lesão original retirada, em serviço médico daquela cidade. Sobre a natureza da neoformação, disse a paciente ignorar o resultado de qualquer exame porventura feito com o material ressecado. Decorrido um ano da intervenção, no sítio da cicatriz, houve recidiva do crescimento, que veio acompanhado por duas lesões satélites.

Ao exame físico da paciente, observou-se no couro cabeludo, região occipital, um nódulo arredondado, medindo $1,5 \mathrm{~cm}$ de diâmetro e exibindo, na superfície, área exulcerada, da qual exsudava líquido serossangüíneo (Figura 1); à direita, ao lado e acima

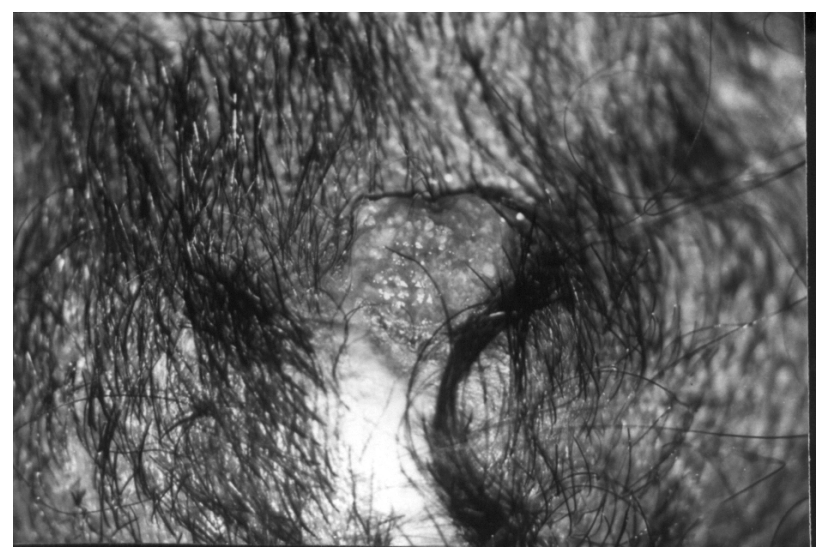

Figura 1 - Pseudomicetoma dermatofítico: massa elevada, firme e de superfície irregular na área nucal. dessa lesão, havia outras duas, com o mesmo aspecto, menores ( $1 \mathrm{~cm}$ de diâmetro) e também exulceradas, que indicavam estar o processo em expansão.

Feita exérese da massa principal, em 31.1.2000, foi ela submetida a exame histopatológico; nos cortes histológicos, observou-se a presença de material constituído em grande parte por tecido de granulação, infiltrado difusamente por células mononucleadas. Pequenos grupos de células gigantes também participavam da reação inflamatória.

No seio do infiltrado, viam-se numerosos corpúsculos de tamanho variável, semelhantes a grãos de micetomas eumicéticos (Figura 2). Eram eles formados por elementos redondos e filamentosos, com membrana espessa e PAS-positiva, recobertos por material eosinofílico, homogêneo e fracamente PAS-

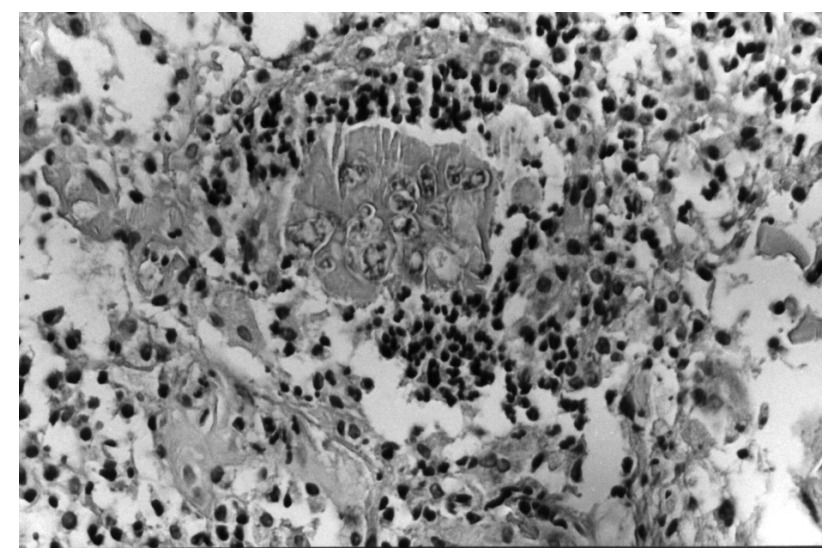

Figura 2 - Pseudogrânulo: elementos hifais e esféricos, pouco nitidos, cercados por substância eosinofílica (material de Splendore-Hoeppli). HE 400X. 
positivo (Figura 3). O material, semelhante à substância de Splendore-Hoeppli, também envolvia externamente

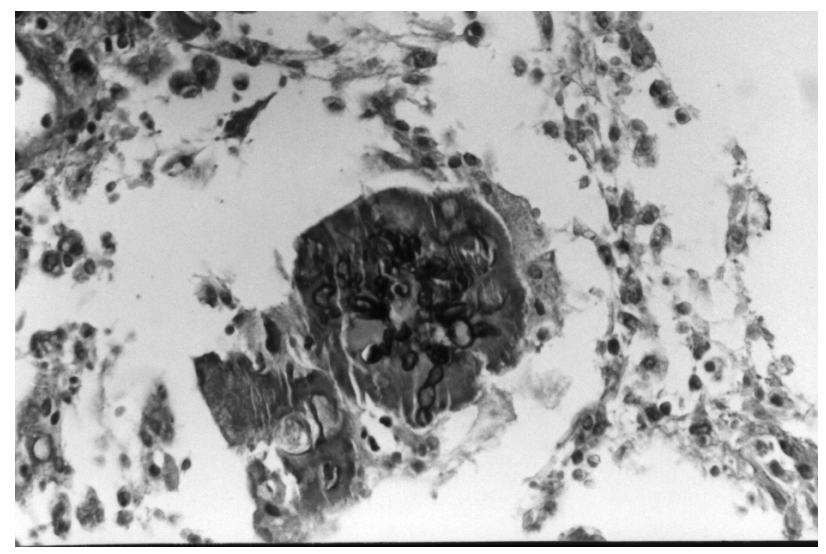

Figura 3 - Pseudogrânulo (estádio inicial): pequeno agregado miceliano, envolvido por material de aspecto homogêneo. PAS micelianc. o conjunto (Figura 4). Os corpúsculos, contendo os filamentos agregados frouxamente (Figura 5),

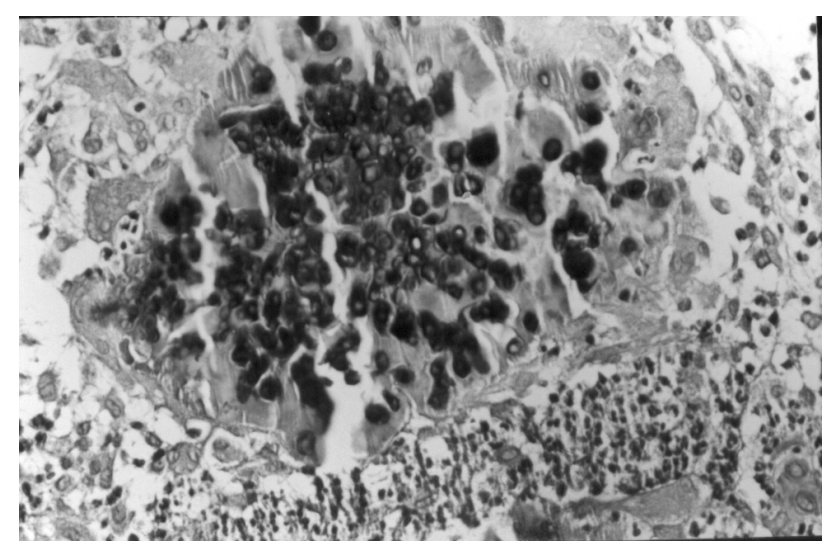

Figura 4 - Grande agregado miceliano frouxo, com precipitado de Splendore-Hoeppli entre as hifas e circundando o conjunto. PAS 400X.

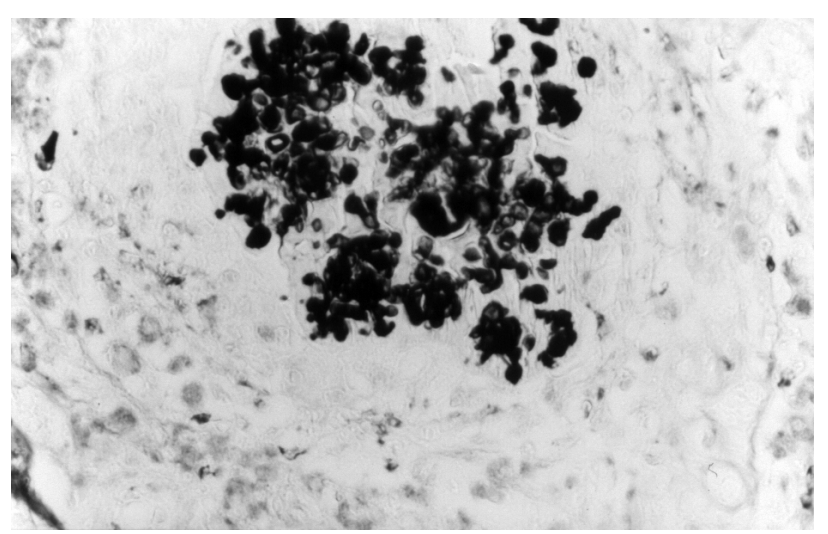

Figura 5 - Filamentos irregulares, impregnados pela prata, formando agregados frouxos na parte central de um pseudogrânulo. Grocott 400X.

apareciam livres no tecido de granulação ou cercados por leucócitos neutrófilos e histiócitos, constituindo esboços de microabscessos ou granulomas mistos. Células gigantes multinucleadas, dispostas em granulomas de corpo estranho, apareciam em torno de algumas das formações.

Firmado o diagnóstico de processo inflamatório granulomatoso devido a agregados de fungos, semelhantes a grãos de micetomas (ou pseudogrãos), procedeu-se à remoção das lesões menores, em
14.2.2000, para semeadura dos tecidos em meios próprios ao desenvolvimento de fungos. Essa medida permitiu isolar-se em cultura o dermotófito Trichophyton tonsurans. Com base nesse isolamento, concluíu-se pelo diagnóstico de pseudomecetoma dermatofítico devido a $T$. tonsurans. Curiosamente, não foram encontradas, em exame posterior, áreas de alopecia no couro cabeludo da paciente, as quais, se presentes, poderiam caracterizar a existência de tinea capitis, fonte do fungo causador dos nódulos. Tentativas de isolamento do fungo também resultaram negativas.

\section{DISCUSSÃO}

Em 1959, Vanbreuseghem \& Vandeputte ${ }^{9}$ publicaram um caso incomum de micetoma fúngico - localizado no couro cabeludo -, em paciente do antigo Congo Belga (República Democrática do Congo). Uma cultura obtida dos grãos, branca e filamentosa, não frutificou, impossibilitando a identificação do fungo. Nos anos seguintes, um tipo semelhante de micetoma, com as mesmas características histopatológicas e localização no couro cabeludo, foi encontrado em outros países 
africanos. A maioria dos casos procedia do Senegal ${ }^{3}$ e de nenhum deles foi isolado o agente.

Camain e $\mathrm{col}^{3}$, em 1971, descreveram novo caso do Senegal, com lesões elevadas no couro cabeludo, ao lado das quais havia focos de tinha microspórica. Culturas desenvolvidas a partir dos grãos e de cabelos parasitados (tipo ectótrix) também não frutificaram. Embora sem identificar a espécie, concluíram os autores que a localização eletiva de certos micetomas africanos - no couro cabeludo e na nuca - estaria ligada ao fato de os agentes patógenos serem fungos parasitas dos cabelos. Eles se desenvolveriam, inicialmente, no interior dos folículos pilosos e invadiriam, depois, o tecido conjuntivoadiposo perifolicular. Aí, além de provocar a formação de massas de tecido de granulação, produziriam os grãos. $O$ lento crescimento do micetoma permitiria, muitas vezes, a cura dos focos de tricofitia imediatamente vizinhos, enquanto a localização profunda continuaria em evolução.

Cerca de uma década depois, Ajello e $\mathrm{col}^{1}$ referiram que sete espécies de dermatófitos - Microsporum audouinii, M. canis, M. ferrugineum, Trichophyton tonsurans, T. mentagrophytes, $T$. verrucosum e T. violaceum - já haviam sido identificadas como produtoras de grãos nos tecidos. Ao todo, eram conhecidos 14 casos, sendo 13 em seres humanos $e$ em um gato (na base da cauda). Além dos casos da África ocidental, outros tinham sido descobertos em países fora do continente africano, inclusive nos Estados Unidos ${ }^{11}$. Embora aceitassem que os chamados micetomas dermatofíticos, com os seus grânulos, tivessem origem em folículos parasitados, sugeriram Ajello e col ${ }^{1}$ que os agregados micelianos formados pelos dermatófitos seriam melhor referidos como pseudogrânulos e que pseudomicetoma deveria ser o termo aplicado a esse tipo de infecção dermatofítica profunda. A sugestão era baseada em cinco pontos de diferença: 1) desenvolvimento seqüencial dos agregados micelianos nos tecidos, desde filamentos individuais ou pequenos grupos de hifas até grandes agregados de micélio (pseudogrãos); 2) abundante material de Splendore-Hoeppli - resultado de uma forte reação humoral por parte do hospedeiro -, circundando os pseudogrãos em todas as fases evolutivas; 3) micélio nos pseudogrãos menos abundante e de entrelaçamento menos compacto do que nos grãos dos micetomas eumicéticos; 4) ausência consistente de qualquer substância cimentante nos pseudogrânulos; e 5) provável origem endógena para os pseudogrânulos, pois os elementos micelianos entrariam na derme por ruptura do epitélio folicular, mecanismo já descrito para o granuloma tricofítico de Majocchi, com o qual, aliás, postularam Ajello e col ${ }^{1}$, manteriam os pseudomicetomas uma relação estreita.

Em revisão da literatura, feita em 1983, Rinaldi e col ${ }^{8}$ listaram 17 casos em seres humanos. A maioria dos pacientes era de raça negra, jovens, com lesões salientes no couro cabeludo, sem fístulas e sem história de trauma. Defenderam o emprego do termo pseudomicetoma para designar a infecção, tendo em conta não apresentarem as lesões os três requisitos essenciais ao diagnóstico dos micetomas verdadeiros: tumefação, presença de fístulas e formação de grãos (microcolônias) verdadeiros.

Pseudomicetomas dermatofíticos, por Microsporum canis, já foram descritos em pacientes sujeitos a terapia imunossupressiva. Além do caso de Barson ${ }^{2}$ incluído na relação de Ajello et $\mathrm{al}^{1}$, em mulher sujeita a tratamento de longa duração para lupus eritematoso sistêmico, um outro caso $^{10}$ mais recente, foi descrito em paciente transplantado. Nos dois casos, as lesões situavam-se nos antebraços. Assinale-se que lesões de granuloma tricofítico de Majocchi, por T. tonsurans, já foram também encontrados em pacientes imunodeprimidos - um transplantado ${ }^{6}$ e outro portador do HIV $-1^{4}$.

$\mathrm{Na}$ literatura nacional, não há registro de casos com lesões de micetoma ou pseudomicetoma dermatofítico. Lacaz e col${ }^{5}$, em 1991, apresentaram nenhuma referência bibliográfica a respeito, apesar da extensa lista sobre dermatofitoses por eles organizada.

\section{REFERÊNCIAS BIBLIOGRÁFICAS}

1. Ajello L, Kaplan W, Chandler FW. Dermatophyte mycetomas: fact or fiction? In: Proceedings of the Fifth International Conference on Mycoses, Caracas, Venezuela. Pan American Health Organization, Washington, DC,Publication n을 396 p. 135-140, 1980.

2. Barson WJ. Granuloma and pesudogranuloma of the skin due to Microsporum canis. Successful management with local infections of miconazole. Archives of Dermatology 121: 895-897, 1985.

3. Camain R, Baylet R, Nouhouayi Y, Faye I. Note sur les mycetomas de la nuque et de cuir chevelu de l'africain. Bulletin de la Société de Pathologie Exotique 64: 447-454, 1999.

4. Hadacek BM, Nassif A, Roux A, Desplaces N, Huerre M, de Bievre C, Aerts J, Raguin G. Trichophyton tonsurans dermatophyte granuloma in an HIV-1 infected patient. British Journal of Dermatology 140: 762-763, 1971.

5. Lacaz CS, Porto E, Martins JEC. Micologia Médica. Fungos, Actinomicetos e Algas de Interesse Médico. 8ª edição, Servier, São Paulo, 1991.

6. Liao YH, Chu SH, Hsiao GH, Chou NK, Wang SS, Chiu HC. Majocchi's granuloma caused by Trichophyton tonsurans in a

cardiac transplant recipient. British Journal of Dermatology 140: 1194-1196, 1999.

7. Padilha-Gonçalves A. Granulomatous dermatophytia. In: Proceedings of the Fifth International Conference on Mycoses, Caracas, Venezuela. Pan American Health Organization, Washington, DC, Publication no 396 p. 141-147, 1980.

8. Rinaldi MG, Lamazor EA, Roeser EH, Wegner CJ. Mycetoma or pseudomycetoma? A distinctive mycosis caused by dermatophytes. Mycopathogia 81:41-48, 1983.

9. Vanbreuseghem R, Vandeputte M. Mycétome de la nuque chez un noir du Congo Belge. Annales de la Société Belge de Médicine Tropicale 39: 227-238, 1959.

10. Voisard JJ, Weill FX, Beylot-Barry M, Vergier B, Dromer C, Beylot C. Dermatophytic granuloma caused by Microsporum canis in a heart-lung recipient. Dermatology 198: 317-319, 1999.

11. West BC, Kwon-Chung KJ. Mycetoma caused by Microsporum audouinii. First report case. American Journal of Clinical Pathology 73: 447-454, 1980 